 \\ 1991 Particle Accelerator Conference \\ Sheraton Palace Hotel, San Francisco, California \\ May 6-9, 1991}

cory-910505--36?

BNL -45724

\title{
A Comparisun of Calculations and Measurements of the Field Harmonics as a Function of Current in the SSC Dipole Magnets*
}

\author{
R.C. Gupta, J.G. Cottingham, S.A. Kahn, G.H. Morgan, P. Wanderer
}

Brookhaven National Laboratory, Ufton, NY 11973, USA

\begin{abstract}
A large number of thort and long superconducting dipole magnets for the Superconducting Super Collider(SSC) have been constracted and mearned for their maguetic field properties at Broolharen National Laboratory (BNL). In this paper we compare the edealations and measurements for the reriation of field harmonies as - function of carrent in $10 \mathrm{~mm}$ aperture and $50 \mathrm{~mm}$ aperture dipole magnets. The primary purpose of this paper is to examine the iron saturation effects on the field harmonies. The field harmonies also change doe to the peraintent carrent in the superconducting wires and due to the deformation of the coil shape becaure of Lorents forces. We discuse the varintion in the sertupole herrisonic $\left(b_{2}\right)$ with current and expluin the differences between the caleulations and measurements. We also diecus the ckew quadrapole harmonic at high field in the long dipole magnets.
\end{abstract}

\section{Introduction}

A comparison between the ealculations and mearurements in a large number and variety of magnets not ouly lllows one to check the reliabirity of computer coden and decign procedure but also allows one to extimate the contribution from cources not inciuded in the enlenlations. The dats on magnet to mugnet rariation allowe one to entimate the uncerteinty to be expected in the foture meguets to be built. The variation in the ealculated harmonics from one computer program to other allows one to entimate the uncerteinty in the computer ealculations. It may be noted that in the present yoke dexign for the SSC dipoles the maximum change in the sertupole harmonic with current can be raried by simply relocating and/or re-aising the otrinleas steel key at the midplane which aligns the top and bottom yoke halves. Therefore, a asstematic difference between the designed and meanured change in $b_{2}$ with current can be empirically corrected. Howerer, before such correction is incorporated a large number of magnets should be analyed.

\section{Procedure}

The abeolute values of multipoles, measured or computed, will not be diecrened in detail in this paper. Howerer, the source of them both in the courtruetion and in the computer modelling and the method ued to compare the relative rariation of feld barmonica as a function of eurrent is diecuened below brielly :

- Persistent Curneat Multipoles are primarily removed from the andyris in these magnets by averaging the mearared moltipotes for the up and down ramp and by itarting the comparieon at $2000 \mathrm{~A}$.
- Geometric Multipoles arising due to variations in the magnet construction are removed by forcing $b_{2}$ to be sero at $2000 \mathrm{~A}$ for euch magnet.

- Model Dependent Mrltipoles present in the computed multipoles due to prectical limitations in eccurately deacribing the conductor geometry, are elso removed by requiring that for each magnet, the $b_{2}$ starts from sero.

\section{Anelysis}

The magnetic dexign of the crom seetion of $40 \mathrm{~mm}$ and $50 \mathrm{~mm}$ dipole cross mection is described eleewhere ${ }^{1,2,3}$. The rariation of field harmonics with respeet to current cen be attributed to two independent feetor. The firnt and the major cource is the non-linear properties of iron. If there is any variation in the magnetic properties of the iron from magnet to magnet then that roold be refleeted in the meanured harmonica and the trander fanction as well. The second source of the variation of the field hermonics with respect to current is the deformation of the coil shape due to Lorents forces. The Lorents force is proportional to $\Gamma^{2}$ (atrictly apenting I $\times$ B). The force on the coil can be resolved in two components - the radial and the arimathal. The radiul component of the force in large on the turas at the midplane. It moves them outward towards the yoke and thas caures a megative change in b2. The arimuthal component of the force acts as a compreasion on the coll. This causes e pocitive change in b2. It should be noted that the arimuthal component of the foree interacts with the pre-compresion applied on the coil daring anembly process. The effect of Lorents force on $b_{2}$ may vary from magaet to magnet due to construetional variations as diecussed below.

\section{Comparison}

In Fig 1(a), we present the calculations (oolid lines) with the computer codes POISSON, MDP(GFUN) and PE2D and the mearurements (dotted lines) in the fint three $50 \mathrm{~mm}$ aperture short mugnets built at Brookhnven National Laboratory (DSA207, DSA208 and DSA200) for the certupole harmonic, b2. The calcalation and mensurements afreed within $1 / 4$ prime unit for predicting the maximam change is $b_{2}$ and change in $b_{2}$ at 6.7 teale $A$ somewhat larger difierence in the is. $i$ smedinte region may be attributed to (a) that the iros yeed in building the magnet was different then the oce presumed in the calculations (b) that some irregulariy shaped magnetic Inminations with punched out cooling chunnels were meed long the length of the magnet (c) that some by change mas be becarse of coil deformation die to Larents forces.

In Fis 1(b), we present the celculations with the computer code POISSON (solid line) and the measurements in seren $40 \mathrm{~mm}$ operture SSC short dipales (dotted lines).

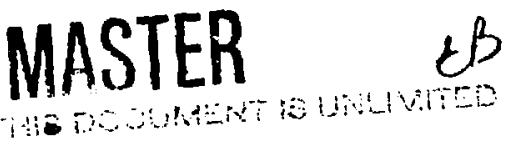



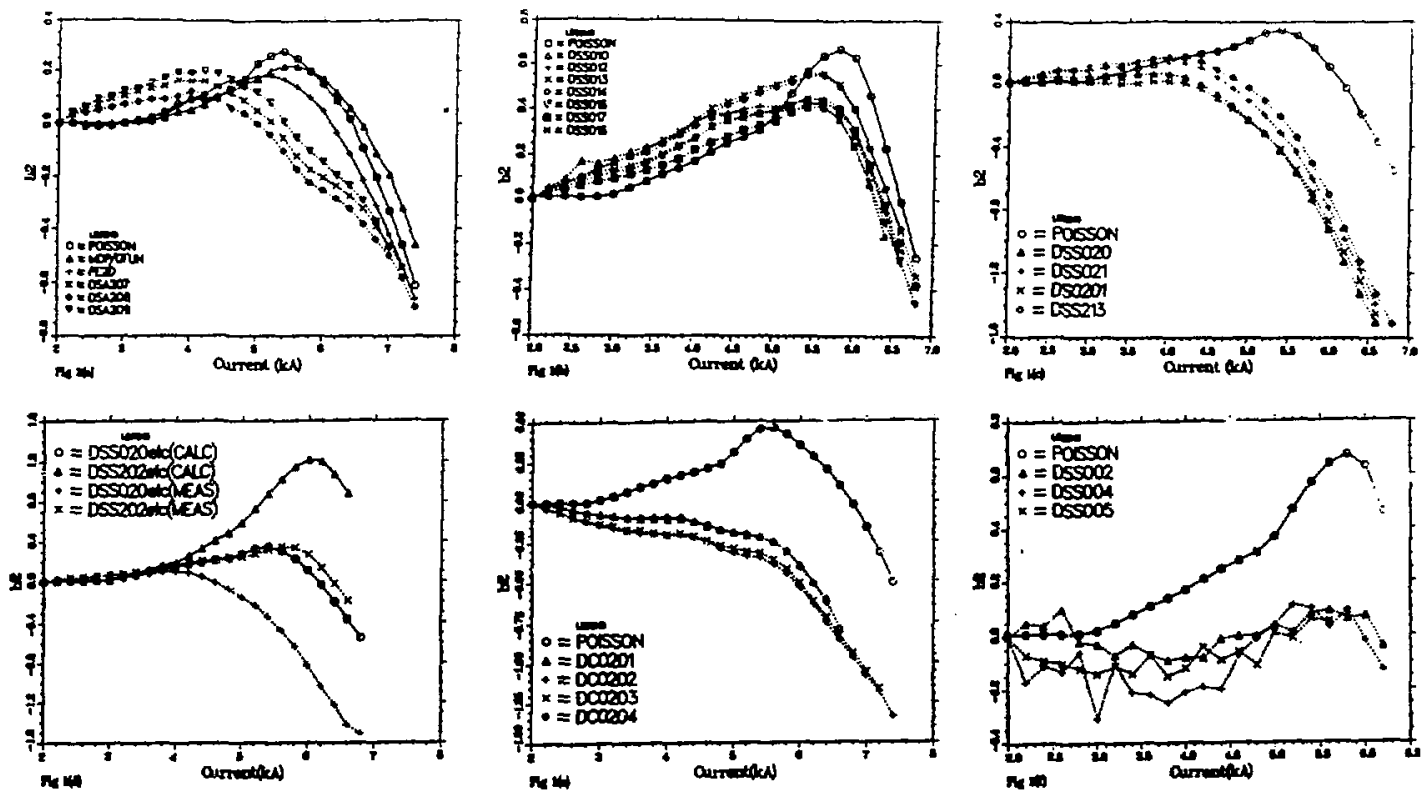

Figure 1: Sextupole harmonic in prime units as a function of current. Solid lines are the computed curves with the code indicated in the legends and the dotted lines are the measured curve for the magnet indicated in the legend.

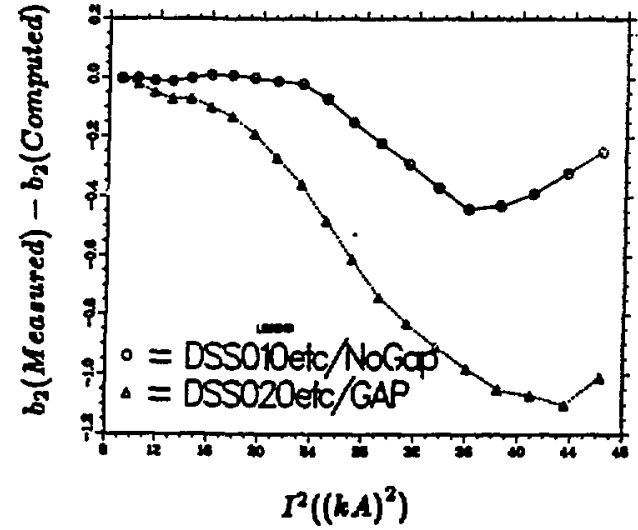

Figure 2: $b_{2}$ (Computed) is mbtracted from $b_{2}$ (Measured) to remore the iron saturation effect in by in the magnets.

The following should be noted. (a) In all computations we used a single meanured B-B table. (b) The irregularly shoped laminations were non-magnetic. (c) There was no gep between the collar and the yoke. Therefore, this is a good example to demonatrate what bind of rariations are to be realistically expeeted between the megnets and between calculations and measurements. In andyaing the variation in the measured relative change in $b_{2}$ (in these and a large number of other magnets) and aleo in andyring the variations in the calculated relative ehange in $b_{2}$ with several computer codes (see Fig $1(a)$ ), we come to the conclusion that $1 / 4$ unit of ancertainty in predicting the relative change in $b_{2}$, is in general a reasonable thing to expect, particularly above $5000 \mathrm{~A}$.

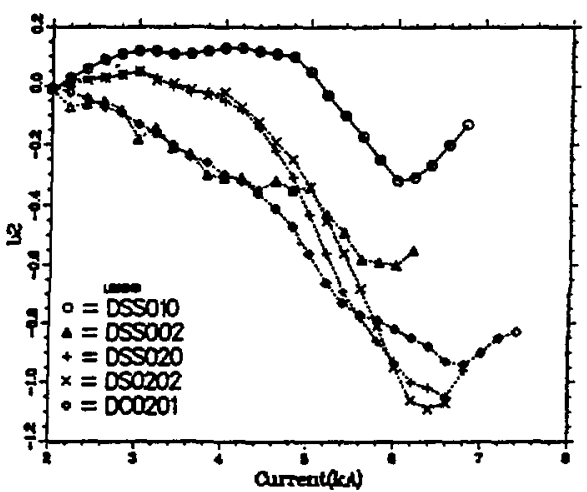

Figure 3: The average difference between the calculations and menaurements in each group of magnets shown in Fis 1.

Now we discuss those magnets where we found a large differences between the calculations and the measurementa. The following major ehanges rere made between the $40 \mathrm{~mm}$ aperture short magneta up to DSS018 and after DSS020. (a) The magnetica of the yoke cross section was changed with the midplane noteh removed and the material of the yoke-yoke alignmeat key changed from magnetic to non-magnetic. (b) The yoke iron was changed with the new iron poscibly heving a different B-H table. (c) A radial gap of $0.1 \mathrm{~mm}$ wa introduced by a yoke die modification. In Fis $1(c)$, we present $b_{2}$ calculations with POISSON (solid line) and $b_{2}$ measurements (dotted lines) in four short dipoles DSS020, DSS021, DS0201 and DS021s. 
A large disagreement between the calculations and measurements can be easily seen. This disagreement was of great concern for a while since it could not be explained by assuming any reasonable change in the magnetic properties of the yoke material. To eliminate the concern about the reliability of computer codes in predieting the effect of the hole at the midplane (caused by the use of the stainless steel key), new to these magnets, the material of the key was changed to magnetic iron in short magnets $D S 0202$ and DS0203. It brought the " $b_{2}$ versus $I$ " carve close to the derign case (see Fig 1(d)). However, the difference between the calculations and measurements in the two cases remained escentially the wame which suggests that the major wource of explanation may be something other then the iron saturation considerations.

The cause of the disagreemeat in presently attributed to the $0.1 \mathrm{~mm}$ gap between the collar and the yoke which gives extre space for the coil to elongate at the midplane dre to the radial component of the Lorents force. It may be mentioned that eren if there is a line to line contact at room temperature, a gap may develop at operating temperature due to a difference in thermal contraction between the yoke and collar material. To study the effect of the Lorents force in this situation, we first compute $\delta b_{2}=b_{2}$ (M easured) $-b_{2}$ (Computed), to remore much of the iron caturation effect: from the measurements. For the measured values we take the arerage of measurement in a number of magnets which use the same magnetic design. This is done for the magnet which had the above mentioned gap (DSS020 and after) and thome which did not (DSS010 to DSS018). In Fig 2, we hare plotted $\delta b_{2}$ against $I^{2}$, which is proportional to the Lorents force. However, once the contact is made between the coil and the collar, there will not be anj more such change in $\delta b_{2}$. In Fig 2, initially there is a little change in $6 b_{2}$ which may be due to a small magnitude of the Lorent: force. $A$ linear negative change in $8 b_{2}$ in the vieinity of 5000 $A$ is attributed to the coil deformation due to Lorent: forces. We note that the change in $\delta b_{7}$ is 1.0 unit in the magnets with gap against the 0.1 unit in the case of magnets with no gap (except the one ereated during cool down). One may also note in Fig 2, that the linear negative change in $\delta b_{2}$ continues to higher current in the magnets with gap, which is consistent with "the extre gap and the Lorents force" explanation. The Lorents force argument is further confirmed by the calculations that $0.1 \mathrm{~mm}$ gap producen this order of change in $b_{2}$. These calculations are, however, model dependent and there could be as much as a factor of two difference depending on how the deformation is eractly included in a model.

An upward swing in $6 b_{2}$ in Fig 2 at high current may be due to the the movement of the pole turn towards the midplane becsuse of the asimuthal component of the Lorents force. It mas also be due to higher pecking factor or due to a higher saturation magnetisation, $\boldsymbol{M}_{n}$, in the iron used in building the magnets then the one presumed in the calculations.

Now we discuss the calculations and meanurements in long dipoles. Though the long dipoles use the name cross section as short dipoles, the saturation properties of them are modified by the proximity of the magnetic cryostat wall which is not present in the short dipoles. The horicontal axis of the cryostat wall is vertically offset from the axis of the coil and yoke by $96.8 \mathrm{~mm}$. At high field when the yoke no longer can contain the total flux in the iron, the un-allowed harmonics, such as $a_{1}$, become a function of current. In Table I, we compare the measurements and calculations for the effect of the cryostat wall on $a_{1}$ and $b_{2}$ at 6500 A. For calculations we take the difference of harmonics computed with and without the cryostat wall. For $b_{2}$ measured the difference between the arerage change in long magnet and short magnet $b_{2}$ is taken. For $a_{1}$ measured in magnets DC0203 and DC0204, an average along the normal axial positions was taken since a mignificant variation along the axik of magnet wes found. In Fig I(e), we present the calculations and meanrements for $b_{2}$ variation with current in long dipoles DC0201, DC0202, DC0203 and DC0204. The difference between the calculations and measurements are similar to those discused abore in DSS020 ahort magnet since the cross rection is the same in these magnets.

Table 1: Computed and measured effects of the proximity of the cryontat wall on the change in $a_{1}$ and $b_{2}$ harmonics between $6500 \mathrm{~A}$ and $2000 \mathrm{~A}$.

\begin{tabular}{|c|c|c|c|}
\hline & Meawured & PE2D & POISSON \\
\hline$a_{1}$ & $-0.3 \pm 0.1$ & -0.27 & -0.38 \\
\hline$b_{2}$ & 0.39 & 0.40 & - \\
\hline
\end{tabular}

In Fig 1(f), we present the calcalations and measurements for $b_{2}$ variation with current in short dipoles DSS002, DSS004, and DSS005. These were the earlier magnets which deliberately had a gap between the collar and the joke.

In Fig 3, we plot the difference between the calculations and measurement in a large number of $40 \mathrm{~mm}$ aperture magnets. Instead of presenting a curve for each magnet we group all similar megnets into a single curve and take the average. We refer each curve to the name of the first magnet in that group (see Fig 1(a) to Fig I(f)). Note that the agreement between the calculation and mesurement is better in those magnets which did not have a gap between the collar and the coil.

\section{References}

1. SSC Conceptual Design Report, SSC-SR-2020, 3/86.

2. G.H. Morgan, et. al., CConstruction and Results of the $50 \mathrm{~mm}$ Short Dipole Magnets", Paper PRA9, this conference (1991).

3. R.C. Gupta, S.A. Kahn, G.B. Morgan, "SSC $50 \mathrm{~mm}$ Dipole Cross Section", Presented at the $3^{\text {rd }}$ International Industrial Symporium on Super Collider (IISSC). Atlante, March 13-15, 1991.

-Work supported by the U.S. Department of energy 